\title{
REMOTE SENSING TIME SERIES ANALYSIS AIMED AT DETECTING AND MONITORING BRAZILIAN IRON ORE MINING DISASTERS
}

\author{
Jorge Antonio Silva Centeno, Regina Tiemy Kishi, Edson Mitishita \\ ${ }^{1}$ UFPR, Federal Univ. of Parana, Centro Politécnico, 81530-000 Curitiba/PR, Brazil - (centeno, rtkishi.dhs, mitishita)@ ufpr.br
}

\author{
Commission III, WG III/7
}

\begin{abstract}
:
Iron mining is one of the main activities of the State of Minas Gerais (Brazil). However, this activity offers significant environmental risks and may harm the local population. In 2019, the Brazil experienced large environmental disaster related to iron mining in the municipality of Brumadinho. The collapse of mining waste water Dam caused the mud spill composed of the mixture of water and tailings minerals that traveled from the dam through the network of local drainage. In this work, it is analyzed the environmental impact of the dam's collapse with the help of remote sensing image using two spectral bands (red and near infrared). The comparative study carried out by analysing Landsat OLI of several months enables evaluating the effect of the event on the water resources and also monitor the evolution of the situation by comparing multiple images. In the first step, direct digital values are measured along the rivers to compare the sediment load in each date, which allows monitoring the situation of the rivers. In a second step, the image series is combined using binary encoding to visualize changes in the catchment. The study shows that the Paraopeba and Córrego do Feijão rivers suffered a great impact from the dam break and that they are slowly recovering from the tragic event.
\end{abstract}

KEYWORDS: change detection, time series, natural disaster.

\section{INTRODUCTION}

Iron mining is one of the main activities of the State of Minas Gerais (Brazil). This activity contributes to the economy of the region and has a long tradition in the state of Minas Gerais. Despite of the advantages, the mining activity also offers environmental risks and can eventually harm the local population. Recently, Brazil has experienced two major environmental disasters related to iron ore mining: Rio Doce (2015) and Brumadinho (2019) with great consequences for the water resources. The collapse of dams of mining waste water offers huge environmental risk because the waste stored in the dam can be highly toxic and can be transported by rivers and water bodies traveling kilometers and even reaching the ocean. In this work, it is analyzed the impacts of the collapse of the dam of Brumadinho on the environment, especially in water resources, with the help of remote sensing image. The turbidity of rivers after the event is analyzed and discussed.

One of the most important applications of remote sensing is the temporal comparison of images with the purpose of analyzing land-cover changes. Change detection is a technique used to determine land cover changes through statistical or arithmetic methods. As the nature of water resources is dynamic by nature, some changes are expected as part of the natural cycle. However, major changes may be caused by human action or, as in this case, by events that alter the natural cycle. In this work, the analysis focuses on the sediment content variation over the water bodies affected by the disaster of Brumadinho. The method aims at detecting changes along time through the analysis of the images after the event. The temporal variation of the digital values of Landsat 8 red (band 4) and near infrared (band 5) channels are analyzed for this purpose, based on the physical properties of water bodies in terms of reflectance. As Yepes ET AL (2018) point out it is possible to estimate the presence of sediment in water using sensor images OLI, because the relation between reflectance and the sediment content follows a pattern that can be modeled by linear regression.
Water absorbs much of the incident electromagnetic energy and has low reflectance in the visible region, between 0.4 and 0.7 $\mu \mathrm{m}$. At wavelengths greater than $0.7 \mu \mathrm{m}$, pure water absorbs all the incident energy. Therefore, the reflected radiation is very low and very low digital values are recorded at such areas. This property becomes important for mapping water bodies, because the low reflectance allows delineating the boundary between water and other object easily.

Water bodies usually contain other elements, dissolved or suspended, that alter the spectral response and appearance. The presence of suspended material, as mud poured out of a reservoir, causes increased reflection of solar energy. The suspended elements like soil particles or debris can change the color significantly. Kallio (2000) emphasizes the advantages of using remote sensing in water quality monitoring programs as follows:

1. It gives a synoptic view of the entire waterbody for more effective monitoring of the spatial and temporal variation.

2. Remote sensing enables having a synchronized view of the water quality within a large area or region.

3. The Landsat archive stores a significant historical collection of data that can be used to analyze water quality over time.

These three advantages are useful in the study of critical environmental disasters, especially when dealing with basins.

Figure 1 shows a comparison of the (theoretical) reflectance of pure water and water with different concentrations of suspended sediments according to Ritchie et al. (1976). It is clear that the turbidity increases reflectance. The reflectance is proportional to the turbidity in the visible region and the effects of turbidity are visible even in the near infrared range. Above $0.9 \mu \mathrm{m}$ water even with sediment load absorbs all the incident energy. 
Novo ET AL (1989) concluded that the type of sediment affects reflectance. The higher the sediment load, the reflectance of a water body is more influenced by sediment, approaching the reflectance of the transported material. Thus, in the near infrared reflectance increases more of that in the visible. The contrast between these two regions can be measured using Equation 1:

$$
\mathrm{C}=(\mathrm{NIR}-\mathrm{VIS}) /(\mathrm{VIS}+\mathrm{NIR})
$$

For the OLI system aboard Landsat 8, near infrared information is stored in the band 5. For the computation of equation 1, the visible red band will be used because this region is strongly affected by sediment contents and the sediment contains high iron concentrations. The potential of this relationship, originally developed for the study of the vegetation, to the study of sediment in water is emphasized by Ke ET AL. (2015). These authors comment also the potential of the index was enhanced when the ETM + aboard Landsat 7 was replaced by the new sensor OLI aboard Landsat 8.

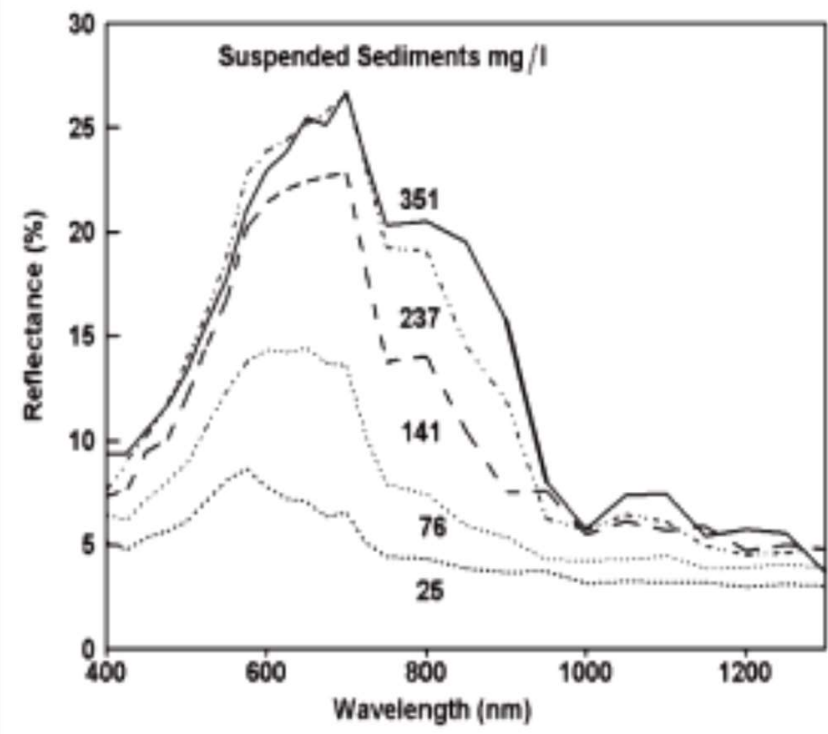

Figure 1. The relationship between reflectance and wavelength as affected by the concentration of suspended sediments (Ritchie et al., 1976).

In a comprehensive review on water quality parameters estimation using remote sensing techniques, Gholizadeh et al (2016) describes the most common methods to estimate sediment concentrations with remote sensing. They point out that turbidity, being an optical property of water, which scatters and absorbs the light, can be used to estimate sediment concentrations in water. Suspended sediments are responsible for most of the scattering and therefore turbidity measurement has often been used to estimate suspended sediment concentrations. As the suspended matter that is transported by water may vary in terms of origin and composition, water color may be affected in different wavelengths. Therefore, sediment concentration estimates with remotely sensed images is performed using the visible and near infrared spectral regions.

Gholizadeh et al (2016) summarizes the approaches used to monitor suspended sediments and turbidity according to the spectral band as displayed in table 1 .
Table 1 - Spectral bands and sensors used in suspended sediments studies with remote sensing, according to Gholizadeh et al (2016).

\begin{tabular}{l|l}
\hline Band Combination & Sensor \\
\hline $\begin{array}{l}\text { green }(0.50-0.60 \mu \mathrm{m}) \text { and red } \\
(0.60-0.70 \mu \mathrm{m})\end{array}$ & Landsat 5-TM \\
& PROBA-CHRIS \\
& IRS-LISS-III \\
\hline blue $(0.40-0.50 \mu \mathrm{m})$ and red $(0.60-$ & Landsat 5-TM \\
$0.70 \mu \mathrm{m})$ & AISA \\
\hline near infrared (NIR) and red $(0.60-$ & MODIS;ALOS- \\
$0.70 \mu \mathrm{m})$ & AVNIR-2 \\
\hline Near Infrared $(0.75-0.90 \mu \mathrm{m})$ & SPOT; Landsat 7- \\
& ETM+; CASI \\
\hline Red $(0.60-0.70 \mu \mathrm{m})$ & Landsat 7- ETM+; \\
& Landsat 5-TM; HICO; \\
\hline Green $(0.50-0.60 \mu \mathrm{m})$ & PROBA-CHRIS \\
\hline
\end{tabular}

\section{THE BRUMADINHO EVENT}

The index described in equation 1 is normally used to study vegetation and is known as the Normalized Difference Vegetation Index (NDVI) but in this study it is used to analyze the sediment load in rivers. Although there are other indexes that aim to monitor water, such as the Normalized Difference Water Index (NDWI), proposed by Gao (1996), the reason why the NDVI is used here is because sediments strongly influence the reflectance in the red and near infrared bands. The aim is not just to detect the presence of water but to assess the water quality changes.

In terms of water bodies, the study was performed at two locations: Along the Côrrego do Feijão and along the Paraopeba River. The Côrrego do Feijão is a small river that received directly the sediment load from the dam. Therefore, it was strongly affected in terms of quality and also its dimensions were changed because of the higher flow rate. It also flows into the Paraopeba River, the second river that was analyzed. The Paraopeba River has higher discharge and therefore better conditions to reduce the concentrations of sediments.

First, the values of the red and near infrared bands were measured along the stream of the Córrego do Feijão, which is the water body that directly received the mud spill. In Figure 2 it is displayed the points where the digital values were read (in blue). The digital values were read in three images in the months after the disaster. The first corresponds to day January/30th, the second to April/20th and the last May/6t. It was intended to use an image per month with approximate interval of 30 days, but it was not possible to obtain an image in February by high cloud cover. The cloud cover in March was also very intense, and affected partially the study area. So it was not used. An image taken before the disaster was also included: September/2018.

In the second step the study object was the Paraopeba River, upstream and downstream of the mouth of the Córrego do Feijão. The number and location of the used points are shown in Figure 3. At the Paraopeba River the values of the near infrared image were analyzed. The 26 points are located near the mouth of the Córrego do Feijão. 


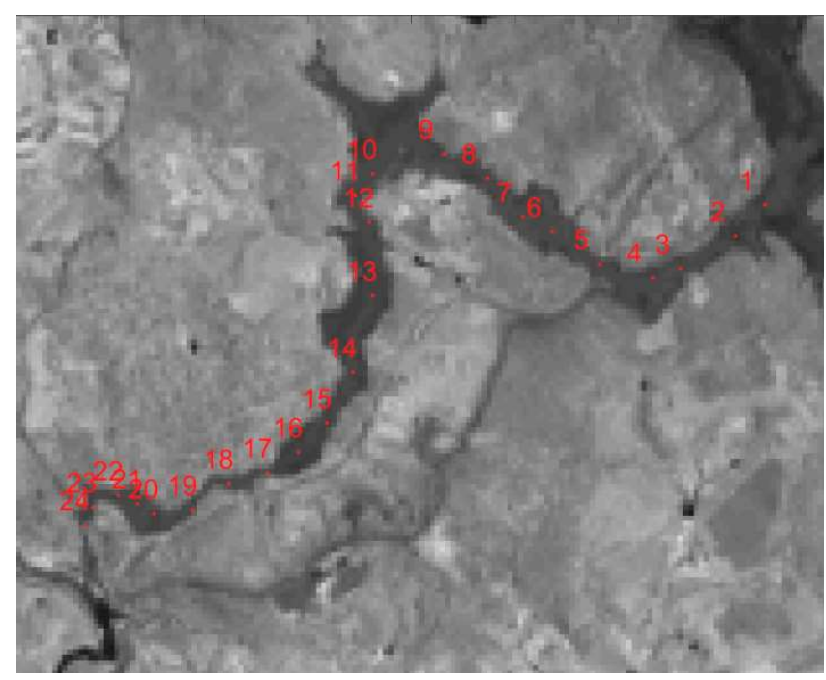

Figure 2 - Location of the points along the Côrrego do Feijão (blue) superposed to the Landsat 8/OLI near infrared band.

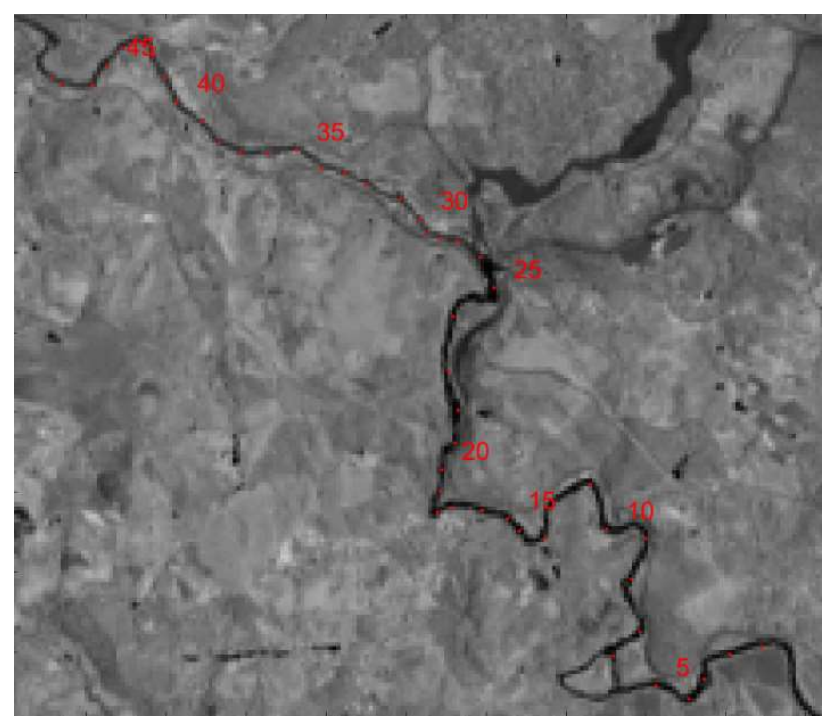

Figure 3-Location of the points where the digital values where read along the Paraopema river superposed to the near infrared image of Landsat 8/OLI.

In a third step the study was extended to the catchment of the Córrego do Feijão river. Again, the contrast between the near infrared and the visible was used, this time to visualize the major changes around the river.

As the aim is to study temporal variations, the available data were combined, summarized, in a single image using the binary encoding approach. Binary encoding is traditionally applied as a feature extraction method when dealing with remote sensing hyperspectral images, as described in Jia and Richard (1993). Is consists in computing a binary image from each single image, what means to reduce the radiometric resolution of each image, and the combine these binary images to build up a new one. The binarization step can be performed by thresholding methods and should store significant information contained in each single image. Image threshold is a very strong operation, with a great information loss. Nevertheless, the fact that many images need to be summarized justifies the approach.
When applied to multitemporal image series, the binary encoding method can be used enable the visualization of changes in long series. Traditionally, because of the monitor color system, three images can be overlaid on the screen to visualize changes as color variations. When dealing with more than three images this task becomes difficult. So, computing a new image, based on the binary representation of each date enables visualizing the reflectance variations. In our experiment, five images are used to compute the new image. The binary images were obtained thresholding the NDVI images with a threshold that separates water from other objects. According to Figure 1, the reflectance in the near infrared is always lower for water, then the NDVI would be negative, contrasting with vegetation or dry soils. Binary encoding of the series was computed according to equation 2 .

$$
\mathrm{B}=\mathrm{p}^{*} 2^{\mathrm{t}},
$$

Where:

$\mathrm{B}$ is the resulting image of binary encoding;

$t$ is the image number in the time series;

$\mathrm{p}$ stands for the digital value in the $\mathrm{t}$-th binary image ( $1=$ water; $0=$ not water).

In this case, five images were used, including more information to better visualize the changes: 2018/09;24; 2019/01/30; 2019/03/19; 2019/04;20 and 2019/05/06.

\section{RESULTS}

The result of binary encoding the time series is displayed in figure $4 \mathrm{a}$ as a gray level image. High values are associated to locations were the index is below the threshold in all dates. This happens when at water bodies and also, in some cases, when bare soil is visible. On the other hand, black pixels represent no water in any image. The interesting areas are gray, because they represent intermediate situations, where the NDVI values are below the threshold only in some images. Figure $4 \mathrm{~b}$ displays a zoom of the Córrego do Feijão catchment. The null values were painted as green to easy the understanding. This image shows the expansion of the river as consequence of the dam break. It is visible that the sediment load covered a large portion of the channel and that the upper river was more affected. A higher dynamic is visible in the lower part of the river. There, some dark gray levels are found, which characterizes the fact that these pixels were below the threshold at only some months.

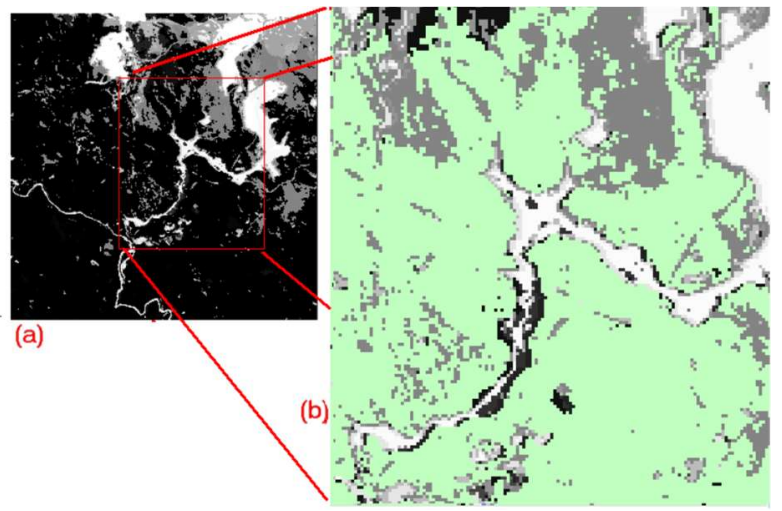

Figure 4 - Binary encoding of the Córrego do Feijão catchment. (a) binary encoded image; (b) zoom of the catchment with null values in green. 
Figure 5 displays the graphics corresponding to each month along the Córrego do Feijão. The raw values were smoothed using a low-pass filter to reduce the presence of noise. The situation before the collapse of the dam is represented with a dotted red line.

In General, it can be said that the values of September 2018 are high, with an average around 0.35 . The high values can be explained with the help of Figure 4. In Figure 4a, the gray levels along the stream are high in the near infrared band mainly because of the presence of vegetation over the stream. On the other hand, in Figure 4b, the values are lower after the dam collapse, because the vegetation was removed and the water absorption prevails.

In Figure 5 the values of 2018 are high. Then, in January, just after the disaster, they fall. 2018 2019. After the collapse of the dam the valley was flooded and covered with wet material. This is consistent, because the water presents high absorption rates in the near infrared and relative high values in the red portion of the spectrum. In the following months, April and May, the values are because the prevailing strong water absorption due.

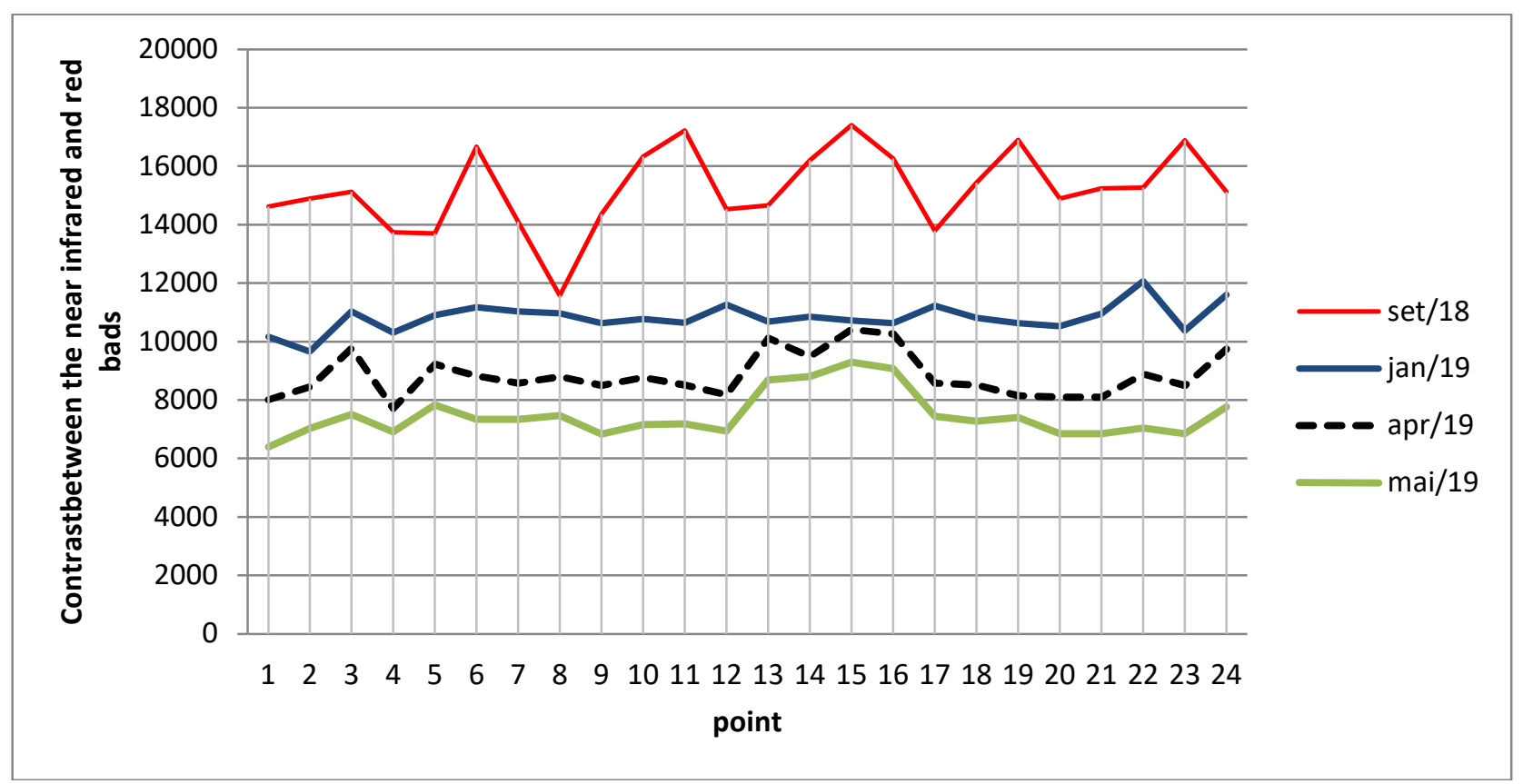

Figure 5- Contrast between the near infrared and Red bands along the Córrego do Feijão.

In the second part of study the sediment load along the Paraopeba River was analyzed, upstream and downstream of the mouth of the Córrego do Feijão. The 26th point is located near the mouth of the stream, for reference purposes.

By examining the values in the near infrared image, Figure 6, it is observed that in the upstream part of the monitored stream, the values are relative similar, which characterizes a normal situation. This is not the case in the downstream part. There are high values after the mud spill in late January. This means that the river was loaded with a severe sediment discharge from the Córrego do Feijão. In April the values are smaller, approaching the situation observed in 2018. This comparison reveals that the sediment load is decreasing each month and the river recovering. 


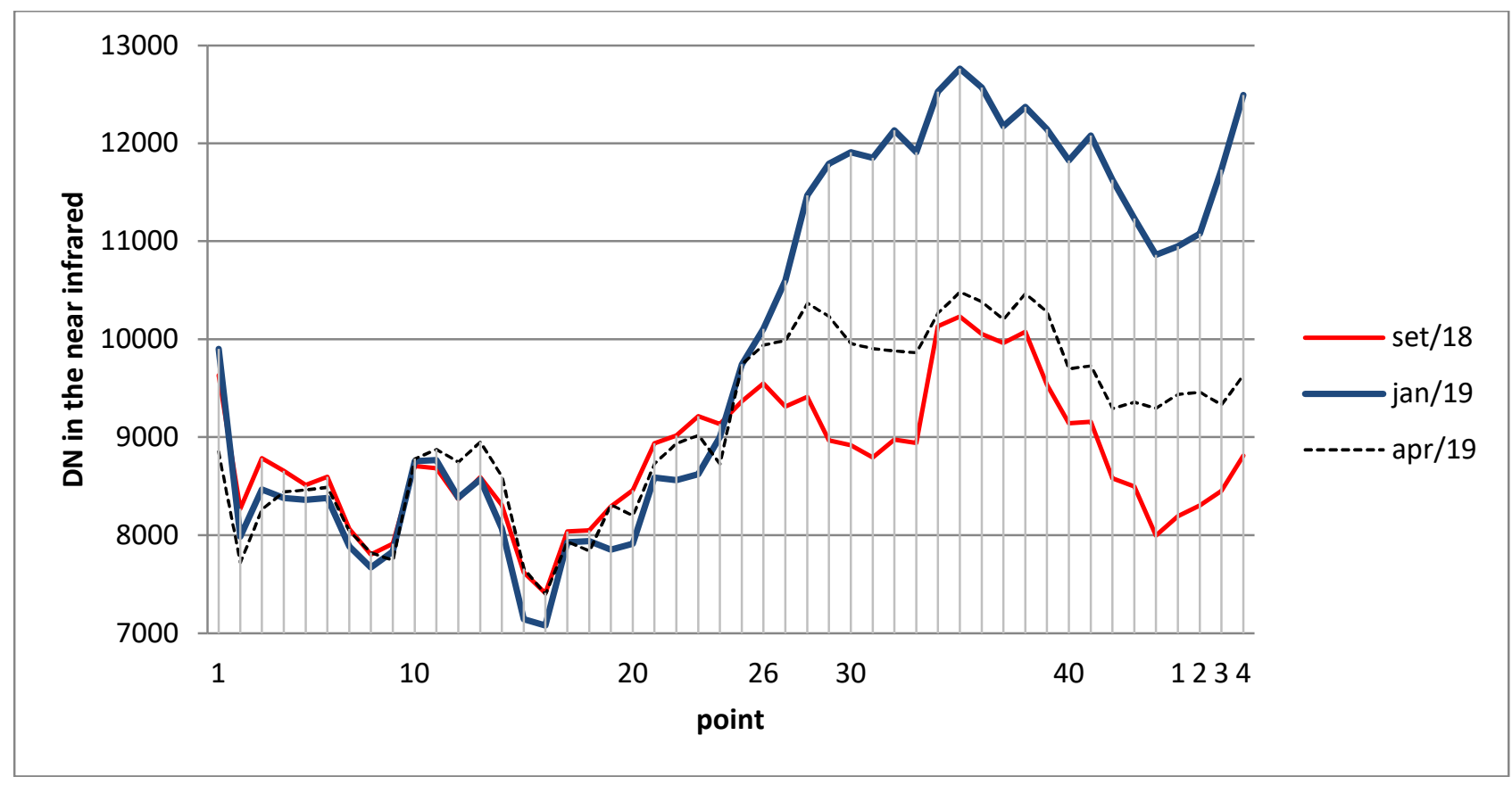

Figure 6 -Digital values in the near infrared image of Landsat/OLI along the Paraopeba river.

\section{REFERENCES}

\section{CONCLUDING REMARKS}

In this paper it is presented the results of a study of changes in turbidity of rivers affected by environmental disaster, being the study case the dam break of Brumadino (MG). It was analyzed how the dam's collapse changed the water resources in the fluvial network with the help of two spectral bands (red and near infrared). The comparative study carried out by analyzing Landsat OLI of several months enables evaluating the effect of the event on the water resources and also monitor the evolution of the situation by comparing multiple images. In the first step, direct digital values are measured along the rivers to compare the sediment load in each date, which allows monitoring the situation of the rivers. The observed data reveals that the reflectance of the rivers increased after the event. It is also observed that the contrast of the red and near infrared bands is a valuable tool for this purpose. As consequence of the collapse, the reflectance increased in the following months. As time passes, the sediment concentration in the larger river (Paraopeba River) is decreasing, showing the natural capacity of the river to recover. On the other hand, at the Córrego do Feijão catchment, the changes are more severe and the mud covered large areas along the channel. The analysis, based on available OLI images from Landsat 8 show that after the event the amount of sediments affected heavily the spectral characteristics of the water, increasing strongly the near-infrared reflectance. Over the following months, this phenomenon has decreased, showing the natural recovery of the water bodies.

\section{AKNOWLEDGEMENTS}

The authors gratefully acknowledge the collaboration of $\mathrm{CNPq}$ (proc. 303279/2018-4) for enabling the development of this research.
Gao, B.C. (1996) DWI - A Normalized Difference Water Index for remote sensing of vegetation liquid water from space. Remote Sensing of Environment, v.58, p.257-266.

Gholizadeh,M.H.; Melesse,A.M.; Reddi, L. (2016). A Comprehensive Review on Water Quality Parameters Estimation Using Remote Sensing Techniques. Sensors (Basel). 2016 Aug; 16(8): 1298. doi: 10.3390/s16081298

Jia, X.; Richards, J.A. Binary coding of imaging spectrometer data for fast spectral matching and classification. Remote Sensing of Environment Vol.43/1, pp.47-53. January, 1993.

Kallio K. (2015). Hydrological and Limnological Aspects of Lake Monitoring. John Wiley \& Sons; New York, NY, USA: 2000. Remote sensing as a tool for monitoring lake water quality; p. 237.

Ke, Y.; Im, J.; Leeb, J. Gong, H.; Ryuc, Y..(2015). Characteristics of Landsat 8 OLI-derived NDVI by comparison with multiple satellite sensors and in-situ observations. Remote Sensing of Environment Vol. 164, July 2015, pp 298-313.

Novo, E.M.M.; Hansom, J. D.; Currant, P. J.. (1989). The effect of sediment type on the relationship between reflectance and suspended sediment concentration. Remote Sensing. Volume 10(7). PP. 1283-1289.

Ritchie, J.; Zimba, P.; Everitt, J. (2003). Remote sensing techniques to assess water quality. Photogrammetric Engineering and Remote Sensing, Vol. 69, No. 6, 695-704.

Yepez, S.; Laraque, A.; Martinez, J.-M.; De Sa, J.; Carrera, J.M.; Castellanos, B.; Gallay, M.; Lopez, J.L.. (2018). Retrieval of suspended sediment concentrations using Landsat-8 OLI satellite images in the Orinoco River (Venezuela) C. R. Geoscience 350 (2018) 20-30. 